\title{
ISIS, Heritage, And the Spectacles of Destruction in the Global Media ${ }^{1}$
}

Ömür Harmanşah

University of Illinois at Chicago

Truth is image, but there is no image of truth.

Marie-José Mondzain

The spectacle is capital accumulated to the point where it becomes image.

Guy Debord

\section{Abstract}

This paper focuses on ISIS's recent destruction of archaeological heritage in Iraq and its (self-) representation in the global media. It is argued that the Islamic State's destruction of archaeological sites and museums as well as historical monuments and local shrines can be seen as a form of place-based violence that aims to annihilate the local sense of belonging, and the collective sense of memory among local communities, to whom the heritage belongs. It is also suggested that the Islamic State coordinates and choreographs these destructions as mediatic spectacles of violence aimed at objects and sites of heritage, which take place as re-enactments or historical performances that are communicated to us through ISIS's own image-making apparatus that utilizes advanced technologies of visualization and communication.

\section{The Scorched Earth}

In a recent article posted on al-Monitor, Massoud Hamed pointed out that in its recent activities, the Islamic State (ISIS) is implementing a scorched-earth policy in

\footnotetext{
${ }^{1} \mathrm{~A}$ shorter version of this article has been published at jadaliyya.com.
} 
North-central Syria, in the region of Kobanê and Tell Abyad, located west of the Euphrates and adjacent to the Turkish border. The area mainly comprises agro-pastoral communities with largely a Kurdish majority (Hamed 2015). The Islamic State militants are reported to have emptied and demolished towns in this region, and are now targeting the countryside: the Islamic State has been burning agricultural fields to devastate the landscapes of livelihood and the sources of subsistence for these communities. Scorched-earth is a harsh, deeply historical military policy that aims to annihilate entire landscapes of livelihood and to deny basic human right to live for local communities even after the battle is over.

One highly prominent aspect of ISIS's program of destruction in Syria and Iraq that has come recently to the media attention recently is their program of cultural heritage destruction that took the form of smashing artifacts in archaeological museums, iconoclastic breaking and bulldozing of archaeological sites, dynamiting of shrines, tombs, and other holy sites of local communities and burning of libraries and archives. In this paper, I focus on ISIS's destruction of archaeological heritage. I argue that this destruction can be seen as a form of place-based violence that aims to annihilate the local sense of belonging, and the collective sense of memory among local communities, to whom the heritage belongs. Therefore heritage destruction can be seen as part and parcel of this scorched-earth strategy described above. I also argue that the Islamic State coordinates and choreographs these destructions as mediatic spectacles of violence aimed at objects and sites of heritage, and these spectacles take place as reenactments or historical performances that are continuously and carefully communicated to us through ISIS's own image-making and dissemination apparatus that increasingly utilizes the most advanced technologies of visualization and communication. I will also pose questions about the relatively weak responses from the archaeological community around the world that rarely went beyond the stereotypical expression of "dismay" to ISIS's heritage destruction. At the same time, I will try to 
answer the why and how of ISIS's dislike of archaeological heritage in the context of late capitalism.

\section{Consuming ISIS}

Since the summer of 2014, the Islamic State has developed an unusual practice of deliberately damaging archaeological sites and museums, alongside its continued attacks on local shrines and holy places that are dear to local communities. In wellpublicized news reports, often issued by ISIS itself, prominent heritage sites including the Mosul Museum, the archaeological sites of Nineveh, Nimrud, and Hatra, and possibly Ashur and Palmyra were reported to have been attacked or threatened to be destroyed. Through a series of carefully disseminated videos and imagery, the world was shown how ancient sculptures were smashed and how the standing architecture in archaeological sites were blown up. These violent acts and their high-tech mediatic representation accomplished many goals at once: from humiliating the local communities to broadcasting a radical ideology of religious fanaticism in order to recruit new transnational militants all the way to defying the common values attached to cultural heritage in the globalized world. And all of this took place in the midst of widespread claims on how ISIS supported its operations partly through looting and trafficking of antiquities ${ }^{2}$.

These constitute a very disturbing development for archaeologists, historians, and heritage specialists of the Middle East from around the world. Since February 2015, ISIS's systematic violence against heritage has gained momentum and caused an

\footnotetext{
${ }^{2}$ United Nations Security Council's Resolution 2199, dated 10 February 2015, states that "all Member States shall take appropriate steps to prevent the trade in Iraqi and Syrian cultural property and other items of archaeological, historical, cultural, rare scientific, and religious importance illegally removed from Iraq since 6 August 1990 and from Syria since 15 March 2011" with the concern that ISIS, AI-Nusrah Front and other terrorist organizations "are generating income from engaging directly or indirectly in the looting and smuggling of cultural heritage items from archaeological sites, museums, libraries, archives, and other sites in Iraq and Syria, which is being used to support their recruitment efforts and strengthen their operational capability to organize and carry out terrorist attacks." See http://www.unesco.org/new/fileadmin/MULTIMEDIA/HO/ERI/pdf/UN SC RESOLUTION 2199 EN.pdf. Accessed June 15, 2015.
} 
unprecedented number of discussion platforms to form, while heroic efforts emerged from western institutions for heritage documentation and preservation. ${ }^{3}$ These efforts seem largely to have been repeating the tired rhetoric of salvaging antiquities in the event of armed conflict from the hands of "violent extremists" and raising global awareness, although they remain largely ineffective in addressing the unique challenge of the Islamic State's counter-heritage campaign that takes place as a media performance on a global scale.

On February $26^{\text {th }}, 2015$, ISIS posted a (now iconic) video on YouTube, showing the deliberate destruction of what seemed to be authentic ancient sculpture in the Mosul Museum and the archaeological site of Kuyunjuk (the citadel of ancient Ninuwa/Nineveh) in Iraqi Kurdistan. Immediately following this posting, a heated debate sprang up in the media and on social networking sites such as Facebook and Twitter on the fate of antiquities in the hands of ISIS. In these debates, the violence was quickly and confidently characterized as medieval iconoclasm, ignorant backwardness, and antiwestern arrogance ${ }^{4}$. Although ISIS removed the video from public view the very next day, it was widely disseminated and obsessively broadcast in thousands if not millions of copies on the Web and recirculated incessantly on news agencies' websites, Facebook profiles, tweets, and blog posts. Many users of these outlets had a visceral reaction to the video and quickly shared the video both to inform others of ISIS's barbaric acts and to declare their own cosmopolitan, humanitarian, civilized condemnation of these uncivilized acts against antiquities. Whereas blog writers and users of Facebook and Twitter usually refrain from posting videos of violence against human bodies, such as

\footnotetext{
${ }^{3}$ One such example is UNESCO's recent initiative Unite4Heritage, a campaign launched by Irina Bokova, the Director-General of UNESCO that aims "to counter the propaganda of cultural cleansing and the destruction of cultural heritage, to support Iraqi youth and to mobilise young people across the world for its protection." See “\#Unite4Heritage campaign launched by UNESCO Director-General in Baghdad" March 28, 2015.

http://whc.unesco.org/en/news/1254

${ }^{4}$ For a critical view of ISIS's iconoclasm, see Elliott Colla "On the Iconoclasm of ISIS"

http://www.elliottcolla.com/blog/2015/3/5/on-the-iconoclasm-of-isis. Accessed 24 July 2015.
} 
beheadings, executions, or pornography, it seemed acceptable to repost the destruction of ancient artifacts. Not only that, but it also gained popularity as a virtual act of resistance against ISIS's inhumanity. In these acts of reposting and incessant global sharing, these videos that had actually been choreographed and carefully edited by ISIS assumed the innocently mediating, objective status of a news item. The social media user reaction was importantly not an act of recoil, but on the contrary an emotional engagement as a familiar, consumerist habit.

For example, in the beginning paragraphs of the $33^{\text {rd }}$ report of the Syrian Heritage Initiative, we are told by Michael Danti and his co-authors that "[r]ecent video footage and photographs released by Islamic State make most reports readily verifiable; in February and March, however, there have been a number of unverified reports posted by Iraqi sources. These reports lack video/photographic evidence and have not as yet been claimed by Islamic State" (Danti et al. 2015; emphasis mine). For the authors of the report, visual media takes on the status of unmediated "readily verifiable" evidence. From a critical art historical point of view, this is a worrisome and rather naïve understanding of how visual media works, for it dangerously depoliticizes the medium of representation and assigns a documentary value to it by virtue of its visuality, completely disregarding its complex relationship to the exercise of power ${ }^{5}$.

Among the archaeological authorities, professional organizations, and experts of Near Eastern archaeology and global heritage, much of the debate has concentrated myopically, on the very content of the videos, followed by a series of stereotypical statements of condemnation and dismay by various professional organizations. Public media ran to the experts: the archaeologists, academics, museum professionals were asked to identify in the video what archaeological artifacts were really destroyed, and which ones were authentic. Hopes were raised that some of the artifacts might be fakes

\footnotetext{
${ }^{5}$ For a critical assesment of the political and ethical status of photography in the context of Middle East, see Azoulay 2012.
} 
or replicas, while speculations concentrated on the fine details of the demolition, such as the metal bars made visible within the core of the statues and the quick and suspicious crumbling of some of the Hatra statues. According to these analyses, multiple Late Assyrian sculpture from the $8^{\text {th }}-7^{\text {th }}$ BCE site of Nineveh and the $1^{\text {st }}-2^{\text {nd }}$ century CE Roman-Parthian site of Hatra were shown to be smashed to pieces or mutilated with the use of various tools such as sledgehammers and drills. In this debate, the video posted by ISIS took the role of objective documentary evidence, through which the destruction of authentic antiquities was studied. Little discussion seems to have appeared in the public media about the authorship of the video, and few questions have been raised about its staged, theatrical, spectacle-like character. The only question about the authenticity of the video was again about its contents: were the sculptures real relics of Mesopotamian heritage or not. This complacent acceptance of ISIS-authored imagery as documentary is possibly more worrisome for our human condition than the destruction of antiquities themselves.

Furthermore, we watch the videos produced by ISIS as evidence for ISIS's destruction of images and therefore identify ISIS militants as iconoclasts, and this claim of idol-breaking is also what ISIS happily embraces with clear references to the early Islamic past, to which I return below. However, we fail to notice the obvious: ISIS's relentless production of images. I then ask: How is it that we are convinced of ISIS militants' hatred of idols and representations, while we consume the very powerful images that constantly flow through the global media, and those videos that have since ironically become some the most iconic representations of contemporary violence against humanity? It is correct that ISIS's own severe and obsessive ideology of shirk (the worship of images or false gods as equals to Allah) will also deny these videos as representations. But this selective and paradoxical understanding of representation must be read precisely as a power discourse, and if we are to be critical of ISIS, we must challenge that power discourse, not accept it. Perhaps the most powerful response to 
ISIS's power discourse through antiquities destruction came from Muslim cartoonists Jehad Awartani and Mehdi "Amo" Rasooli, whose work play with similar paradoxes between the violent practices and the political rhetoric of ISIS while touching on the common equation of global humanity with global heritage (Figures 1, 2 and 3). ${ }^{6}$ The cartoonists give the western media and academics an important lesson: the uncritical reading of ISIS's visual productions as documentary simply endorses and helps ISIS's propaganda machine.

\section{ISIS and the spectacles of destruction}

As an art historian, I am concerned less about what the ISIS videos show, but more interested in the production of images themselves, i.e. why the video was produced by ISIS in the first place, how the video presents these acts of material violence, and how it is received by its audience. Here for a brief moment, just for the sake of argument, I would like us to treat the ISIS videos not as items of archival resource, something to be mined for objective information, but as artifacts of ideological discourse, which will then allow us to question their documentary status. By doing this, we can also challenge the video's documentary status by pointing out its performative character. In the ISIS video from February 2015, carefully costumed performers with devoutly coiffed beards are shown in the Mosul Museum attacking sculpture on pedestals: Given the fact that ISIS is an organization composed of volunteers coming from a vast variety of nationalities from countries in Europe, the Middle East and beyond, it is not hard to recognize the choreographed nature of the act and the costumes and looks of its actors, which are commented in the above mentioned cartoons. Using clumsy and explicitly primitive gestures, the militants use the force of their bodies to topple the statuary, and use sledgehammers and pick axes to crumble them to pieces. These performances highlight

\footnotetext{
${ }^{6}$ See Christiane Gruber, "Ignored and Unreported, Muslim Cartoonists Are Poking Fun at ISIS" http://www.newsweek.com/ignored-and-unreported-muslim-cartoonists-are-poking-fun-isis-332040. Accessed July $25^{\text {th }}, 2015$.
} 
a direct and bodily attack on the statues, and can be imagined as a re-enactment of the $7^{\text {th }}$ century CE destruction of idols in the Ka'aba, which they frequently and explicitly cite. This is an atavistic performance that deliberately abducts the legacy of a medieval heritage and appropriates it as religious genealogy to serve the very enrichment of ISIS's ultra-modern imagery-machine. As the authors of Afflicted Powers put it: "Terror can take over the image-machinery for a moment - and a moment, in the timeless echo chamber of the spectacle, may now eternally be all there is." (Boal et al. 2008: 28).

The sections of the video that involve the Assyrian colossal sculpture at the gates of Nineveh are less successful: ISIS actors had to switch to electric drills to mutilate the faces of the giant lamassu figures, which were made from "the hard stone of the mountain with a grain-like texture," according to the $7^{\text {th }}$ century BCE Assyrian king Sennacherib's (705-681 BCE) imperial inscriptions, which boast about opening a new quarry for the construction of his palace (Moorey 1994: 344) (Figure 4-5). Toppling these immense stone creatures is a daunting task. Despite their failure in destroying the giant guardians of the Assyrian gates, I would argue that the ISIS enactors deliberately chose these figures for acts of defacing, particularly due to their animate and intimidating posture, their eerily hybrid features bringing together a human face, bull's or lion's body and eagle's wings, and their immense, superhuman scale (Figure 4). Toppled and sledgehammered statuary of Hatra is coupled with the defacing of the Assyrian magical beings, all of which present to us a perfect re-enactment and historicized archaic celebration of late antique and medieval idol-breaking rituals in varying degrees of success. I provide this performance-based analysis of ISIS videos as an alternative to the heritage-conscious responses of academics in the Middle East and the western world, which take the videos as pure documentary evidence. 


\section{Heritage discourse}

It is also important to contextualize the powerful affect of these performances with respect to our contemporary global regime of monetary and historical value that is attached to antiquities. The destruction of the Mosul antiquities in ISIS-propagated visual media derives its efficacy and power directly from the very notion of authenticity and from the relic-like status of antiquities globally, as well as from the political economy of the circulation of antiquities in global markets, which seems to be an everflourishing industry (Figure 6). This global industry is supported and sustained by the increasing demand for illicit antiquities around the world (See e.g. Kersel 2012). ISIS's performative acts of destruction appropriate these transnational associations and value systems of global heritage to choreograph effective spectacles in an attempt to allure their sympathizers and patrons, recruit further fanatics, humiliate local communities while annihilating their sense of heritage, and offend the humanitarian West. This is the multi-directional goal and effect of ISIS's acts of heritage destruction.

As indicated by many postings on various blogs ${ }^{7}$, ISIS had disseminated false news a few weeks prior to the video's release that the walls of Nineveh in Mosul were being dynamited. This news item of ambiguous authorship had been circulated globally in the social media by millions. Later, archaeologists and officials in Mosul confirmed that no such destruction had (yet) taken place, although these statements were hardly reported in the popular media. Cultural heritage specialists around the world took a deep breath of relief until the video was released in late February. If we assume to some level that the destruction of antiquities did take place in Nineveh and the Mosul Museum, and continues to take place, then it can be argued that the global media representation of the destruction took place before the act of destruction itself and not

\footnotetext{
${ }^{7}$ See for example, Sam Hardy, "Islamic State has toppled, sledgehammered and jackhammered (drilled out) artefacts in Mosul Museum and at Nineveh" https://conflictantiquities.wordpress.com/2015/02/26/iraq-mosulmuseum-nergal-gate-nineveh-destruction/. Accessed July 14, 2015.
} 
after. In this case, the so-called representation of the destructive event precedes the actual act of destruction, which is to say that the documentary claim of the visual imagery propagated by ISIS should be considered by necessity as false. This only demonstrates the powerful role of new media technologies on the physical acts of destruction itself and reverses our hierarchies of reality versus representation.

\section{ISIS's Heritage Destruction as a Hyperreal Reality Show}

I argue here that ISIS's media performances operate much like a reality show that effectively mobilizes the consumerism of visual media. The production of the videos and photographic imagery that presents us with ISIS's horrendous acts of violence, whether against human bodies, sacred buildings, cultural heritage and archaeological sites or museum antiquities are often the real purpose of their interest. It is important to point out that to produce these videos, they have deliberately chosen (in a calculated way) ancient statuary that are fitting for the historicized enactment of idol destruction and not any of the hundreds of other smaller antiquities present in the Mosul museum. These videos and photographic imagery are staged performances where the physical acts of violence and destruction form the consequence of their filmic activity. We must responsibly consider the possibility that what we treat on our Facebook profiles, tweets and blogs as documentation of violence is in fact the raison d'etre of ISIS's biopolitics. I extend this argument to suggest that the Assyrian and Parthian sculptures in Mosul were destroyed (if they were indeed destroyed) for the sole purpose of producing the video. We cannot and should not see the filmic representation as a document. Its stark reality lies in its representation, much like the mentality of the production of a reality show. The main purpose is the production of the show: What happens in it is indeed real, although completely staged. Contrary to what has been argued about ISIS as an anachronistic and medieval entity in its ideology and mentality, I argue that ISIS is a super-modern phenomenon, incorporating the most powerful tools of hyperreality in 
disseminating their violent acts. Accordingly, we must find better ways to deal with ISIS's propaganda machine more critically, and go beyond frantically trying to identify what in their videos was destroyed and what was not.

\section{Re-enactments of iconoclasm}

Finally, this discussion brings us back to the heated debates in the aftermath of Taliban government's dynamiting of rock-cut Buddha reliefs of the Bamiyan valley in March 2001, which provoked thoughtful academic responses such as Finbarr Barry Flood's detailed analysis in Art Bulletin 84 (Flood 2002). As with the Bamiyan Buddhas, ISIS's destruction of Mosul antiquities, especially sculpture were characterized as a modern act of iconoclasm. I propose that the element of iconoclasm exists in ISIS's acts only as a historical reference, a rhetoric, and perhaps more powerfully as an archaizing re-enactment of the idea. Iconoclasm is understood as a historically pervasive tactic of removing the animacy, agency, effective power, and present liveliness of images, and is attested in the history of all monotheistic religions, not just Islam (Ellenbogen and Tugendhaft 2011).

Iconoclastic acts has also been used as a strategy to counter the powerful memory of a political power, as in the gauged eyes of an image of Akkadian king from the Mesopotamian Bronze Age (Figure 7), the erased faces of the Egyptian Queen Hatshepsut's statuary in Deir el Bahari and the Roman practices of damnatio memoriae (Elsner 2003). Yet iconoclastic acts have rarely involved a complete breaking of idols and imagery - rather, they have involved the mutilation of dangerous components of liveliness, such as the head, eyes, and face. If we consider ISIS's acts as iconoclasm, then we will have to accept that they considered the museum antiquities as animated and posing a threat to their own religious practice. Do we really think this is the case? Furthermore, labeling ISIS's acts as iconoclasm naively categorizes them as timeless acts against figuration. On the contrary, I consider these as performative acts of producing 
imagery of violence in the public sphere, while using the discursive tools of imagebreaking in that particular performance by citing histories of iconoclasm. I prefer to see ISIS's destructive work as operating in the realm of what Bruno Latour famously called "iconoclash" - the contemporary and perpetual image wars in the public sphere, both destructive and constructive, and driven by advanced technologies of capitalist hypermodernity, new media mobilization, and the global economy of the extensive consumption and regeneration of violent imagery (Latour 2002). In this sense, I see ISIS not at all as an anachronistic religious phenomenon, but as emerging from the very dynamic culture of our super-modern moment. It is through a critical engagement with this supermodernity that we can develop the intellectual tools needed to respond responsibly to a phenomenon such as ISIS, which continues to take lives and annihilate local communities as I write this. 


\section{Bibliography}

Azoulay, Ariella; 2012. The Civil Contract of Photography. Cambridge MA: MIT Press, Zone Books.

Boal, Iain A.; T.J. Clark, Joseph Matthews, and Michael Watts; 2008. Afflicted Powers: Capital and Spectacle in a New Age of War. Chicago: Verso 2008.

Danti, Michael D.; Matt Trevithick, Tate Paulette, Allison Cuneo, Kathryn Franklin, and David Elitzer; 2015. "Syrian Heritage Initiative Weekly Report 33 (March 23, 2015)". Accessed June 15, 2015. http://www.asor-syrianheritage.org/syrian-heritageinitiative-weekly-report-33-march-23-2015/

Ellenbogen, Josh and Aaron Tugendhaft (eds); 2011. Idol Anxiety. Stanford CA: Stanford University Press.

Elsner, Jaś; 2003. Iconoclasm and the Preservation of Memory. In Monuments and Memory, Made and Unmade, edited by Robert S. Nelson and Margaret Olin. The University of Chicago Press: Chicago and London, 209-232.

Finbarr Barry Flood; 2002. "Between Cult and Culture: Bamiyan, Islamic Iconoclasm, and the Museum" The Art Bulletin 84/4: 641-659.

Hamed, Massoud; 2015. "The Islamic State's scorched earth policy in Kobani" Al-Monitor. Accessed June 15, 2015. http://www.al-monitor.com/pulse/originals/2015/06/islamic-state-burnagriculture-lands-kobani-syria.html\#ixzz3dC0qMk00

Harmanşah, Ömür and Christopher Witmore; 2007. "The endangered future of the past," International Herald Tribune. December 21, 2007. http://www.iht.com/articles/2007/12/21/opinion/edwhitmore.php 
Kersel, Morag M.; 2012. The Value of a Looted Object - Stakeholder Perceptions in the Antiquities Trade. In The Oxford Handbook of Public Archaeology, edited by J.

Carman, C. McDavid and R. Skeates. Oxford: Oxford University Press; 253-274.

Latour, Bruno; 2002. "What is iconoclash? Or is There a World Beyond the Image Wars?" in Iconoclash: Image Wars in Science, Religion and Art. Bruno Latour and Peter Weibel (eds.). The MIT Press, 14-37.

Moorey, P.R.S.; 1994. Ancient Mesopotamian Materials and Industries: the Archaeological Evidence. Clarendon Press.

Figures

Figure 1. ISIS militants decapitate the "heritage of humanity." Jehad Awartani. Published with the permission of the author.

Figure 2. ISIS militants carry a decapitated ancient Assyrian lamassu sculpture from Nineveh, Iraq. Mehdi "Amo" Rasooli. Published with the permission of the author.

Figure 3. ISIS militants threaten an Assyrian king's statue. Mehdi "Amo" Rasooli. Published with the permission of the author.

Figure 4. Guardian gate sculpture from the Palace of Assyrian king Sargon II at DurSharruken. From P. E. Botta and E. Flandin, Eugène. Monument de Ninive. Band 1 Architecture et sculpture. Paris, 1849: PI. 45.

Figure 5. Orthostat relief from the Assyrian king Sennacherib (705-681 BCE)'s "Palace without Rival" at Nineveh (Southwest Palace), Court VI, depicting the transport of quarried gate sculpture. British Museum. 
Figure 6. The so-called "Guennol Lionness," an ancient Near Eastern figurine which was sold at a Sotheby's Auction on December 5, 2007 for an exorbitant amount. See Harmanşah and Witmore 2007.

Figure 7. Copper head of Akkadian ruler (2250-2200 BCE). Iraq Museum, Baghdad.

\section{Bio}

Ömür Harmanşah is Associate Professor of Art History at the University of Illinois at Chicago. He is the author of two monographs, Cities and the Shaping of Memory in the Ancient Near East (Cambridge University Press 2013) and Place, Memory, and Healing: An Archaeology of Anatolian Rock Monuments (Routledge 2015). Since 2010, he has been directing Yalburt Yaylası Archaeological Landscape Research Project, a regional survey in central western Turkey. He specializes on the archaeology of the ancient Near East, as well as questions of landscape and place and political ecology. 